\title{
Repairing the foundation: the future of primary care
}

$\mathrm{P}$ rimary care has long been viewed as the bedrock of our health care system. In Barbara Starfield's classic definition, it is "that level of a health service system that provides entry into the system for all new needs and problems, provides person-focused (not disease-oriented) care over time, provides care for all but very uncommon or unusual conditions, and coordinates or integrates care provided elsewhere or by others." In recent years, however, there has been a distinct shifting of the ground. Nowhere is this more evident than in the declining number of medical school graduates who are opting for a career in family medicine. Despite renewed efforts to reverse the trend, family medicine accounted for $75 \%$ of unfilled positions after the first round of this year's Canadian residency match. ${ }^{2}$

If primary care is floundering, it is not for want of effort. There are quite remarkable examples of individual physicians and communities building strong primary health care practices and networks. For example, the Group Health Centre in Sault Ste. Marie, founded in 1963 on the model of old-style (i.e., cooperative) American HMOs, now covers the primary and specialty care needs of 56000 enrolled patients and has made exemplary gains in the management of chronic disease. ${ }^{3}$

But there have also been disappointments. Despite the calibre of their services, Quebec's ambitious, provincewide, community-based primary care clinics, the CLSCs, are poorly utilized and have not brought about fundamental structural change. ${ }^{4}$ It would seem that the barriers to effective primary care delivery are still underestimated, despite the intensive research and evaluation that has been carried out over the last 30 years. Among the contributing factors are medical and health sciences curricula that lean increasingly toward subspecialization, an emphasis on technology and evidence over human factors and communication, fee schedules that, negotiated in the backrooms of medical politics, favour specialists over generalists, health planning and policy development that give token attention to regional and community problems, and inadequate investment in the information systems so vital to the integration and coordination of primary care.
These impediments are social and political at their core. Prevailing societal values are evident in our pursuit of efficiency, our emphasis on specialist education and our reliance on public-private partnerships. It is easier to make a business case for a new PET scanner than for an inner-city primary care organization. But why is it that the obvious gains that could be bought with improved health informatics have not spurred an adequate investment in the infrastructure of electronic patient records? An effective and sustainable primary care system demands the coordination and integration of services, and hence the efficient and reliable transfer of information. We have the technology: but not quite. Few doctors and no patients can access medical records electronically; the patient "smart card" is still little more than a smart idea. Imagine having to see the manager to find out your bank balance; imagine being told it will take days or weeks to retrieve your file. An inaccessible health record should be just as unimaginable in this day and age. Our failure to adequately fund a pan-Canadian electronic health record framework to supply personalized, confidential, just-in-time information for patients and their physicians is woeful.

The erosion of primary care as the foundation and point of entry of our health care system will result in a continuing emphasis on technology-intensive costly secondary and tertiary care, making it increasingly difficult to maintain a universal public health care system. On May 16-19, experts and policy-makers will present new research and new ideas at the National Primary Care Conference in Winnipeg; we look forward to their proposals for renovation and repair. - CMAF

\section{References}

1. Starfield B. Primary care: balancing health needs, services, and technology. 2nd ed. New York and Oxford: Oxford University Press; 1998. p. 8-9.

2. Sullivan P. Students still ambivalent about family medicine. CMAf 2004;170(9):1380.

3. Rachlis M. Prescription for excellence: how innovation is saving Canada's health care system. Toronto: HarperCollins; 2004. p. 101-5.

4. Romanow RJ. Building on values: the future of bealth care in Canada. Saskatoon: Commission on the Future of Health Care in Canada; 2002. Available: www.healthcarecommission.ca (accessed 2004 Apr 16). 